\title{
The Ross procedure in patients aged less than 18 years: The midterm results
}

Gianluca Brancaccio, MD, PhD, Angelo Polito, MD, MPH, Stiljan Hoxha, MD, Fabrizio Gandolfo, MD, Salvatore Giannico, MD, Antonio Amodeo, MD, and Adriano Carotti, MD

Objective: This study reviews a single-center experience with the Ross procedure in infants and young children.

Methods: From November 1993 to March 2012, 55 children aged less than 17 years underwent a Ross procedure. The patients ranged in age from 2 days to 17 years (median, 5.9 years). Thirteen patients were infants, and 18 patients were preschool children. The predominant indication for the Ross procedure was aortic stenosis. Twenty-seven patients (49\%) with left ventricular outflow tract obstruction underwent a modified Ross-Konno procedure. Twenty-five patients ( $45 \%$ ) had undergone 40 previous cardiac procedures. Preoperatively, 3 patients showed severe left ventricular dysfunction, with 2 of the patients requiring intubation and inotropic support. Concomitant procedures were performed in 11 patients $(20 \%)$. Nine patients underwent mitral valve surgery, and 2 patients underwent subaortic membrane resection.

Results: Patients were followed up for a median of 66 months (range, 3 months to 17 years). Overall survival at $1,2,5$, and 10 years was $84.9 \%$. Hospital mortality rate was $13 \%$ ( $7 / 55$ patients). All deaths occurred in neonates or infants, except 1 who was aged less than 4 years. Freedom from reoperation for autograft failure was $100 \%$ at 1 year, $96.7 \%$ at 5 years, and $73.7 \%$ at 10 years. During follow-up, 7 patients required a reoperation on the autograft for dilatation and severe aortic insufficiency. Freedom from reoperation for the right ventricular outflow tract replacement was $56.1 \%$ at 10 years.

Conclusions: The low rate of autograft failure demonstrates that the Ross procedure is an attractive option for the management of aortic valve disease and complex left ventricular outflow tract obstruction in the pediatric population. However, alternative options must be considered in adolescents and young adults. (J Thorac Cardiovasc Surg 2014;147:383-8)

The optimal operative management of aortic valve disease in children and young adults remains controversial. The Ross operation, first described more than 40 years ago, is aimed at the treatment of aortic valve disease and based on autograft transplantation of the native pulmonary valve into the aortic position and reconstruction of the pulmonary outflow tract with an homograft. ${ }^{1}$ The Ross operation allows growth of the autograft and avoidance of anticoagulation therapy. ${ }^{2}$ However, because the need for multiple reinterventions for the replacement of the right ventricular outflow tract (RVOT) substitute and neoaortic root dilatation leading to aortic regurgitation have been reported, ${ }^{3-5}$ one could argue that the Ross procedure might turn a single-valve disease into a double-valve pathology. ${ }^{6}$

The goal of this study was to report a single-institution experience with the Ross operation in neonates, infants,

\footnotetext{
From the Department of Cardiac Surgery, Ospedale Pediatrico Bambino Gesù, IRCCS, Rome, Italy.

Disclosures: Authors have nothing to disclose with regard to commercial support.

Received for publication Sept 3, 2012; revisions received Nov 18, 2012; accepted for publication Feb 13, 2013; available ahead of print March 13, 2013.

Address for reprints: Gianluca Brancaccio, MD, PhD, Department of Cardiac Surgery, Ospedale Pediatrico Bambino Gesù, Piazza S. Onofrio, 5-00165 Rome, Italy (E-mail: gbrancaccio70@ hotmail.com).

$0022-5223 / \$ 36.00$

Copyright (C) 2014 by The American Association for Thoracic Surgery http://dx.doi.org/10.1016/j.jtcvs.2013.02.037
}

children, and young adults and to describe the incidence of pulmonary autograft dilation and insufficiency, as well as the need for reintervention on the autograft or homograft.

\section{MATERIALS AND METHODS}

The Committee on Clinical Investigation at Bambino Gesú Children's Hospital approved the study and waived the requirement for written informed consent.

\section{Subjects}

Between November 1993 and March 2012, all patients aged less than 18 years who underwent a Ross procedure at the Bambino Gesù Children's Hospital were included. All patients underwent surgery with the standard technique of cardiopulmonary bypass with bicaval cannulation and moderate hypothermia. Myocardial protection was achieved by intermittent infusion of blood cardioplegia.

A standard technique of complete root replacement with coronary transfer was used for the Ross procedure. No pledgets were used. In case of left ventricular outflow tract (LVOT) obstruction, a modified Ross-Konno procedure was performed. The ventriculoplasty incision was patched by an extension of attached infundibular free wall muscle harvested with the autograft. A pulmonary/aortic homograft or a heterograft was used for RVOT reconstruction.

The primary outcome measure was the need for late reintervention. The secondary outcome variables were represented by 28-day mortality and late survival, late right ventricle to pulmonary artery (RV-PA) conduit, and autograft failure. For the purpose of this analysis, RV-PA failure was defined as the presence of insufficiency or stenosis of the conduit with a mean gradient of at least $30 \mathrm{~mm} \mathrm{Hg}$ and right ventricular pressure at least 2/3 to 


\section{Abbreviations and Acronyms \\ $\mathrm{CI}=$ confidence interval \\ LVOT $=$ left ventricular outflow tract \\ RVOT $=$ right ventricular outflow tract \\ $\mathrm{RV}-\mathrm{PA}=$ right ventricle to pulmonary artery}

respect the systemic arterial pressure; autograft failure was defined as neoaortic root dilatation with $z$ score changes from hospital discharge to follow-up or changes in neoaortic valve insufficiency grade from discharge to follow-up.

The immediate postoperative result was assessed by transesophageal echocardiography in all patients after surgery. Further echocardiography studies were obtained preoperatively, postoperatively, and annually thereafter. Autograft valve function, homograft or RVOT conduit valve function, and left ventricular function were assessed by M-mode, 2-dimensional echocardiography and color flow Doppler.

\section{Statistical Analysis}

STATA version 11.1 data analysis and statistical software (StataCorp LP, College Station, Tex) was used for statistical analysis. Continuous variables are reported as median (range), and categoric variables are reported as number (proportion). The $t$ test and Wilcoxon rank-sum test were used for continuous variables as appropriate; the chi-square and Fisher exact tests were used for categoric variables as appropriate. Survival curves for freedom from RV-PA, autograft failure, and late survival were obtained by use of the Kaplan-Meier method, and comparisons were performed with the log-rank test. The continuous variables examined included age and weight at treatment, which were dichotomized at a cutoff of 1 year and $10 \mathrm{~kg}$, respectively, to explore the effect of younger age and low body weight on outcomes. Additional multivariate survival analyses for the separate end points of RV-PA and autograft failure or late survival were performed by means of Cox proportional hazards multiple regression models. The selection of independent variables for the model was based on statistical significance in univariable testing. All comparisons were 2-sided.

\section{RESULTS}

A total of 55 patients underwent the Ross operation at the Ospedale Pediatrico Bambino Gesù during the study period. Demographic and selected operative characteristics for these patients are summarized in Table 1. Median age and weight at surgery were 5.9 years (range, 2 days-17 years) and $18 \mathrm{~kg}$ (range, 3.5-110), respectively. Follow-up information was available for $74 \%$ of the 55 patients. Median follow-up time was 66 months (range, 3 months to 17 years).

The preoperative hemodynamic indication for the Ross procedure was represented by a combination of aortic stenosis and regurgitation for 31 patients $(56 \%)$. In 27 patients (51\%) with LVOT obstruction, a modified Ross-Konno procedure was performed. In 2 patients with Shone's anomaly, concomitant mitral valve surgery was required.

Twenty-five patients $(47 \%)$ had undergone a total of 40 previous cardiac procedures. These procedures are listed in Table 1 . Three patients $(5.5 \%)$ showed severe preoperative left ventricular dysfunction; of those, 2 patients required preoperative mechanical ventilation and inotropic support.

Whenever possible, a pulmonary homograft (31 patients, $51 \%$ ) was preferentially used to reconstruct the RVOT. An aortic homograft was used in 3 patients $(6 \%)$, and a heterograft was used in 23 patients $(42 \%)$. The median diameter of the replaced pulmonary valve was $19 \mathrm{~mm}$ (range, $10-26 \mathrm{~mm}$ ).

Concomitant procedures were performed in 11 patients. A concurrent mitral valve surgery was performed in 9 patients $(17 \%)$; of those, 6 patients underwent mitral repair and 3 patients underwent valve replacement. The remaining 2 patients underwent subaortic membrane resection. Two patients who underwent the Konno-Ross operation required insertion of a permanent pacemaker for a complete atrioventricular block.

\section{Twenty-Eight-Day Mortality and Late Survival}

Seven patients $(13 \%)$ died within 28 days from surgery. Three patients were neonates, 3 patients were infants, and 1 patient was a preschool child. Of those patients, 1 showed signs of aortic valve endocarditis with severe insufficiency and died of multiple organ failure. Six patients underwent a Ross-Konno procedure, with concomitant mitral valve surgery in 2 . Two neonates with critical aortic valve stenosis underwent urgent Ross operation for severe aortic insufficiency after balloon valvuloplasty.

At the univariate level, age less than 1 year, weight less than $10 \mathrm{~kg}$ at surgery, and longer cardiopulmonary bypass time were associated with 28-day mortality (Table 2). Because the number of events was low, it was not possible to seek an independent association between demographic variables and 28-day mortality by using a multivariable logistic regression model.

Overall survival at $1,2,5$, and 10 years was $84.9 \%$ (range, 72.1\%-92.2\%) (Figure 1). We were not able to identify any independent association between perioperative characteristics and late survival (Table 3).

\section{Late Reintervention}

Overall freedom from all-cause reoperation was $97.6 \%$ (range, 84.6\%-99.7\%), 86.7\% (range, 70.7\%-94.3\%), and $48.1 \%$ (range, $27.2 \%-66.2 \%$ ) at 1,5 , and 10 years, respectively (Figure 2).

\section{Reoperations on the Autograft}

Overall freedom from reoperation for autograft failure was $100 \%, 96.7 \%$ (range, $78.6 \%-99.5 \%$ ), and $73.7 \%$ (range, $47.2 \%-88.4 \%$ ) at 1,5 , and 10 years, respectively. Six patients $(11 \%)$ required reoperation on the autograft; the main mechanism was represented by severe aortic insufficiency in 5 patients and aortic root dilatation in 1 patient. One patient required simultaneous reoperation of both the 
TABLE 1. Patient demographics and preoperative characteristics of the study population $(n=55)$

\begin{tabular}{lc}
\hline \multicolumn{1}{c}{ Variable } & Median (range) or N (\%) \\
\hline Age & 5.9 y $(2 \mathrm{~d}$ to $17 \mathrm{y})$ \\
Neonates $(<1 \mathrm{mo})$ & $4(7)$ \\
Infants $(<12 \mathrm{mo})$ & $9(16)$ \\
Preschool child $(1-5 \mathrm{y})$ & $18(33)$ \\
Child $(5-10$ y) & $9(16)$ \\
Adolescent $(10-17$ y) & $15(27)$ \\
Weight at surgery $(\mathrm{kg})$ & $18(3.5-110)$ \\
Gender (M/F) & $39 / 16$ \\
Redo operation & $25(45)$ \\
Aortic balloon valvuloplasty & $20(36)$ \\
Surgical valvotomy & $4(7)$ \\
Surgical valvuloplasty & $2(4)$ \\
Coarctation repair or aortic arch plasty & $13(24)$ \\
Subaortic membrane resection & $7(13)$ \\
VSD repair & $3(5)$ \\
VSD repair and coarctation repair & $2(4)$ \\
Mitral valve surgery & $3(5)$ \\
IAA-A repair/IAA-B repair and VSD repair & $3(5)$ \\
Others & $4(7)$ \\
Preoperative aortic valve disease & \\
Mixed AS/AI & $31(56)$ \\
AS & $14(25)$ \\
AI & $8(15)$ \\
Bicuspid aortic valve & $15(27)$ \\
\hline
\end{tabular}

$V S D$, Ventricular septal defect; IAA, aortic arch interruption; $A S$, aortic stenosis; $A I$, aortic insufficiency.

autograft and the homograft. All patients received a mechanical valve replacement except 1 patient who underwent aortic valve repair. Two additional patients affected by autograft valve insufficiency were waiting for reoperation at the time of the study. Multivariable analyses showed that aortic steno-insufficiency is independently associated with an increased risk of autograft failure (Table 4 and Figure 3). Autograft failure is a time-related event, with a significant late hazard 12 years after Ross surgery (Figure 4).

TABLE 2. Univariate analysis of demographic and selected perioperative characteristics and 28-day mortality

\begin{tabular}{lc}
\hline \multicolumn{1}{c}{ Risk factors } & 28-d mortality $\boldsymbol{P}$ \\
\hline Age $<1$ y & $<.001$ \\
Weight at surgery $<10 \mathrm{~kg}$ & $\mathbf{. 0 0 1}$ \\
Sex (female) & .97 \\
Diagnosis & .34 \\
Aortic stenosis & \\
Aortic steno-insufficiency & \\
Aortic insufficiency & \\
Mitral lesion & .64 \\
ECC & $<.001$ \\
Aortic crossclamp & .08 \\
\hline
\end{tabular}

ECC, Extracorporeal circulation.

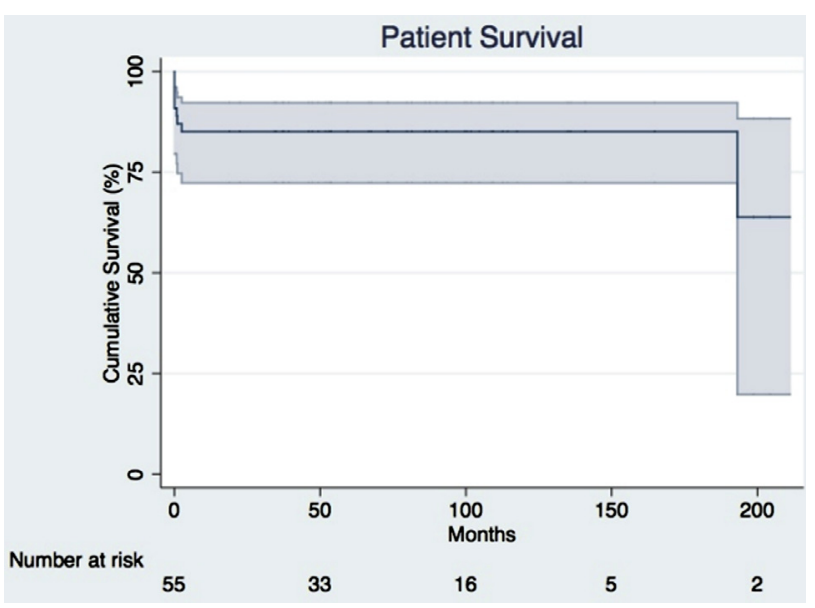

FIGURE 1. Kaplan-Meier survival curve for 55 patients undergoing Ross operation. Shaded areas indicate $95 \%$ confidence intervals (CIs).

\section{Reoperations on the Right-Sided Conduit}

Twelve patients $(22 \%)$ required RV-PA conduit reoperations; of those, 2 patients required 2 reoperations. The indication for conduit reintervention was predominant stenosis in all patients. Overall freedom from reoperation for the RVOT replacement was $97.7 \%$ at 1 year, $89.7 \%$ at 5 years, and $56.1 \%$ at 10 years. Univariate and multivariate analyses showed that the use of a heterograft for RVOT reconstruction compared with the use of a homograft was associated with increased hazards to undergo late reoperation (Table 4 and Figure 5).

\section{DISCUSSION}

The Ross operation is a double root procedure that has the advantages of a viable neoaortic root with excellent hemodynamics, freedom from hemolysis, potential of growth in infants and young children, and a low risk of endocarditis. ${ }^{7}$ The operation requires reconstruction of the RVOT with a nonviable valve and is a technically demanding procedure with an increased operative risk and concerns for long-term durability. The early postoperative mortality rates reported in the literature are low, ranging from $1.5 \%$ to $3.5 \%$ in larger series. ${ }^{8,9}$ We reported a slightly higher 28 -day mortality rate $(13 \%)$ compared with reports from other centers. ${ }^{10,11}$ We believe this difference is mainly due to the younger age of our cohorts at surgery; the median age at surgery was 5.9 years, and $25 \%$ of patients were aged less than 1 year and $60 \%$ of patients were aged less than 5 years. Six of 7 patients who died in our cohort were aged less than 1 year. Preoperative severe hemodynamic impairment as shown by the need of urgent Ross operation in 2 neonates also plays a major role in increasing the likelihood of early mortality. Moreover, the concomitant high rate of Konno modification among patients who died early may suggest that postoperative myocardial dysfunction significantly contributed to the 
TABLE 3. Risk factors for late survival and late intervention: Results of univariable and multivariable analysis

\begin{tabular}{|c|c|c|c|c|}
\hline \multirow[b]{2}{*}{ Risk factors } & \multicolumn{2}{|c|}{ Unadjusted } & \multicolumn{2}{|c|}{ Adjusted } \\
\hline & Late survival $P$ & Late reintervention $P$ & Late survival* $P$ & Late reintervention* $P$ \\
\hline Age $<1$ y & $<.001$ & .83 & - & - \\
\hline Weight at surgery $<10 \mathrm{~kg}$ & $<.001$ & .61 & - & - \\
\hline Sex & .83 & .31 & - & - \\
\hline \multicolumn{5}{|l|}{ Diagnosis } \\
\hline Aortic stenosis & .23 & .26 & - & - \\
\hline \multicolumn{5}{|l|}{ Aortic steno-insufficiency } \\
\hline \multicolumn{5}{|l|}{ Aortic insufficiency } \\
\hline Mitral lesion & .82 & .53 & - & - \\
\hline Conduit type (heterograft vs homograft) & .05 & .02 & - & $\begin{array}{l}3.51(1.14-10.76) \\
0.03\end{array}$ \\
\hline
\end{tabular}

*Hazard ratio $(95 \% \mathrm{CI})$.

higher mortality rate in our cohort of patients. Our data confirm that younger age, weight at surgery, and longer bypass time are associated with early mortality. ${ }^{12}$

The Ross procedure is an advantageous approach to relieve the hypoplastic aortic annulus. ${ }^{13}$ The excellent exposure of the LVOT and the ventricular septum facilitates the enlargement of the Konno modification. In our series, 27 patients had a concomitant Konno procedure; no restenosis of LVOT was observed during follow-up. Nine patients with LVOT obstruction and mitral valve disease underwent a Ross-Konno procedure with concomitant mitral valve surgery. Because 3 valves may be at risk for postoperative complications, concomitant mitral valve surgery at the time of the Ross procedure is thought to be associated with a poor outcome. ${ }^{13,14}$ In our series, we could not confirm the association between mitral valve disease and early mortality. On the basis of our data, we believe that combining the Ross procedure and mitral valve surgery is a feasible and safe surgical approach.

The rate of structural and nonstructural autograft deterioration with the need for reoperation in pediatric patients

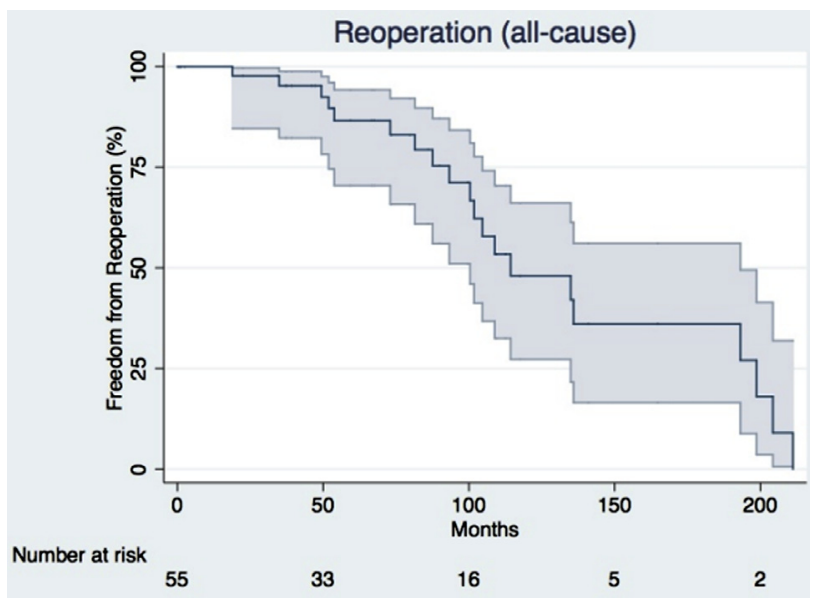

FIGURE 2. Kaplan-Meier freedom from all-cause reoperation. Shaded areas indicate $95 \%$ CIs. ranges from $0.24 \%$ to $2.82 \%$ per patient-year, with a pooled mean of $1.38 \%$ per patient-year. ${ }^{15}$ In our cohort, freedom from reoperations on the autograft was $96.7 \%$ at 5 years and $90 \%$ at 8 years. However, autograft failure becomes apparent after 12 years in accordance with an actuarial estimate of $73 \%$. Aortic regurgitation was the leading cause of reoperation based on nonstructural valve failure with root dilatation. A systematic review of the literature conducted by Takkenberg and colleagues ${ }^{15}$ showed that younger age may be associated with decreased autograft durability. This study also showed that significant variability between studies in terms of autograft deterioration was present and suggested that some of the variability may be due to differences in surgical techniques. In our study, the root replacement technique was used in all patients, using a maximum of 1 to $2 \mathrm{~mm}$ of muscle below the valve and in some cases an additional reinforcement of the aortic annulus with a strip of autologous pericardium. We believe this technique might help prevent annular dilatation. We do not use any other form of stabilization (ie, putting the autograft into the Valsalva tube) to facilitate the growth of the autograft.

The incidence of structural and nonstructural degeneration of conduit was reported to be $1.6 \%$ per patient-year, ranging from $0.7 \%$ to $3 \%$ in pediatric series. ${ }^{15}$ In our series, freedom from pulmonary valve replacement after the Ross procedure was $56.1 \%$ at 10 years of follow-up. All patients underwent RVOT conduit replacement for conduit stenosis secondary to outgrowth or degeneration. Our results indicate that reoperation for conduit replacement is likely to be necessary during late childhood or adolescence. On the basis of our data showing the higher durability of a homograft compared with a heterograft for RVOT reconstruction, our policy is now to use a pulmonary homograft for RVOT reconstruction and to place the largest possible conduit at the time of the operation.

The Ross operation has demonstrated excellent results in both children and adults. ${ }^{9,10,16}$ In particular, given the possibility of autograft growth, the Ross operation is 
TABLE 4. Risk factors for late right ventricle to pulmonary artery and autograft failure: Results of univariable and multivariable analysis

\begin{tabular}{|c|c|c|c|c|}
\hline \multirow[b]{2}{*}{ Risk factors } & \multicolumn{2}{|c|}{ Unadjusted } & \multicolumn{2}{|c|}{ Adjusted } \\
\hline & RV-PA conduit failure $P$ & Autograft failure $P$ & RV-PA conduit failure* $P$ & Autograft failure* $\boldsymbol{P}$ \\
\hline Age $<1$ y & .47 & .65 & - & - \\
\hline Weight at surgery $<10 \mathrm{~kg}$ & .44 & .53 & - & - \\
\hline Sex & .12 & .31 & - & - \\
\hline Diagnosis & .17 & .04 & & \\
\hline Aortic stenosis & & & & (Reference) \\
\hline Aortic steno insufficiency & & & & $6.28(1.14-34.66)$ \\
\hline Aortic insufficiency & & & & .03 \\
\hline Mitral lesion & .35 & .47 & - & - \\
\hline Conduit type (homograft vs heterograft) & .004 & - & $\begin{array}{l}4.24(1.16-15.47) \\
0.03\end{array}$ & - \\
\hline
\end{tabular}

*Hazard ratio $(95 \% \mathrm{CI})$.

considered the surgical procedure of choice for neonates and infants. ${ }^{12,17}$ Complex aortic valve repair has been described in infants with respectable intermediate-term results. ${ }^{18}$ Nonetheless, as a result of the unique technical challenges posed by small infants, the Ross operation still remains the more effective surgical solution in this population. Furthermore, $51 \%$ of patients in our cohort required a Konno modification to address LVOT obstruction, which would not be treated by aortic valve repair alone. By contrast, alternative surgical options with comparable longterm results (eg, aortic valve repair and valve replacement with stentless valves or bioprosthesis) are available for adolescents and young adults. ${ }^{19,20}$ Nonetheless, some authors argue that the Ross operation might place 2 valves at risk for single valve disease. ${ }^{6,21}$ There have been an increasing number of reports describing dilatation of the aortic annulus, sinuses of Valsalva, and sinotubular junction after the Ross procedure., ${ }^{4,22}$ Histologic studies have demonstrated that the pulmonary wall can show fracture and a general disorganization of elastin fibers when

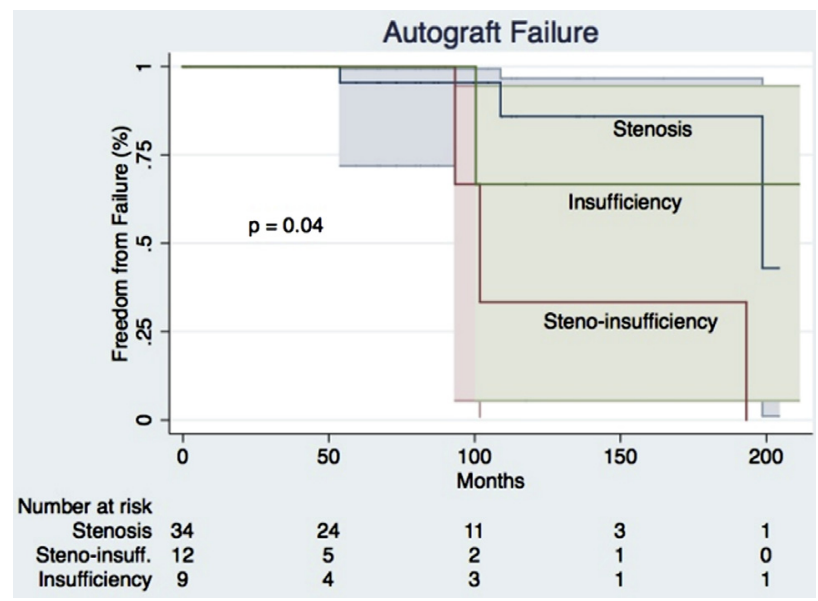

FIGURE 3. Kaplan-Meier freedom from autograft failure according to preoperative aortic lesion. Shaded areas indicate $95 \%$ CIs. exposed to the high-pressure systemic circulation. ${ }^{23}$ On the other hand, Yacoub and El-Hamamsy ${ }^{24}$ describe "biomechanics and maintained viability of the aortic root after aortic valve replacement are major determinants of longterm outcomes." In particular, the native aortic root is a dynamic living structure that undergoes active changes in size and shape during the cardiac cycle, so that the Ross procedure is the only operation that guarantees long-term viability of the aortic valve. ${ }^{24}$ In our experience, the Ross operation has demonstrated excellent outcome within the first decade after surgery followed by an increased rate of reoperation in the second decade. Our institutional policy for aortic valve disease is based on the Ross procedure for infants, neonates, and children, and aortic valve repair or aortic valve replacement with bioprosthesis or stentless in adolescents or young adults.

\section{CONCLUSIONS}

Our data show that the Ross procedure is an attractive option for the management of aortic valve disease and complex LVOT obstruction in a pediatric population with high long-term survival. However, a high early mortality rate might have to be considered when performing this

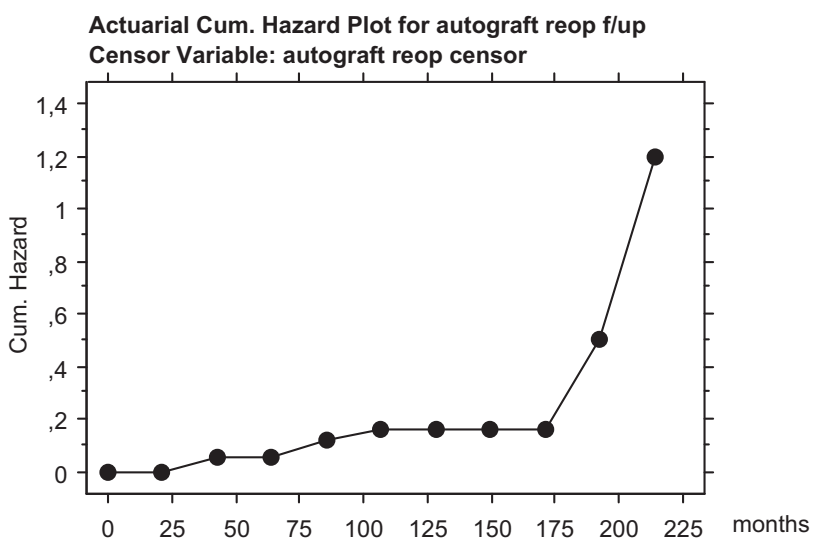

FIGURE 4. Actuarial cumulative hazard plot for autograft failure. 


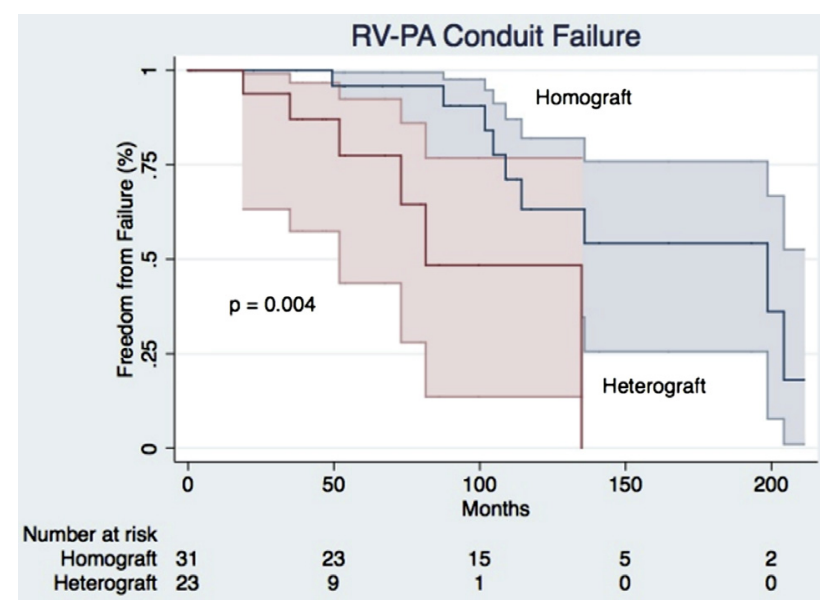

FIGURE 5. Kaplan-Meier freedom from RV-PA conduit failure. Shaded areas indicate $95 \%$ CIs. $R V$-PA, Right ventricle to pulmonary artery.

procedure in infants or in case of multilevel left-sided heart obstructions. The use of a heterograft and the presence of aortic steno-insufficiency are independently associated with RV-PA conduit and autograft failure, respectively. The rate of reoperation for autograft failure is low and encouraging especially within the first decade after surgery. By contrast, the high rate of reoperation for a right-sided conduit in childhood and adolescence should favor alternative surgical options, such as aortic valve repair or replacement.

\section{References}

1. Ross DN. Replacement of aortic and mitral valves with a pulmonary autograft. Lancet. 1967;2:956-8.

2. Moidl R, Simon P, Aschauer C, Chevtchik O, Kupilik N, Rodler S, et al. Does the Ross operation fulfill the objective performance criteria established for new prosthetic heart valves? J Heart Valve Dis. 2000;9:190-4.

3. Pasquali SK, Shera D, Wernovsky G, Cohen MS, Tabbutt S, Nicolson S, et al. Midterm outcomes and predictors of reintervention after the Ross procedure in infants, children, and young adults. J Thorac Cardiovasc Surg. 2007;133:893-9.

4. David TE, Omran A, Ivanov J, Armstrong S, de Sa MP, Sonnenberg B, et al. Dilation of the pulmonary autograft after the Ross procedure. J Thorac Cardiovasc Surg. 2000;119:210-20.

5. Horer J, Stierle U, Bogers AJ, Rein JG, Hetzer R, Sievers HH, et al. Re-interventions on the autograft and the homograft after the Ross operation in children. Eur J Cardiothorac Surg. 2010;37:1008-14.
6. Laudito A, Brook MM, Suleman S, Bleiweis MS, Thompson LD, Hanley FL, et al. The Ross procedure in children and young adults: a word of caution. $J$ Thorac Cardiovasc Surg. 2001;122:147-53.

7. Al-Halees Z, Pieters F, Qadoura F, Shahid M, Al-Amri M, Al-Fadley F. The Ross procedure is the procedure of choice for congenital aortic valve disease. J Thorac Cardiovasc Surg. 2002;123:437-41.

8. Elkins RC, Thompson DM, Lane MM, Elkins CC, Peyton MD. Ross operation: 16-year experience. J Thorac Cardiovasc Surg. 2008;136:623-30.

9. Frigiola A, Varrica A, Satriano A, Giamberti A, Pome G, Abella R, et al. Neoaortic valve and root complex evolution after Ross operation in infants, children, and adolescents. Ann Thorac Surg. 2010;90:1278-85.

10. Hraska V, Krajci M, Haun C, Ntalakoura K, Razek V, Lacour-Gayet F, et al. Ross and Ross-Konno procedure in children and adolescents: mid-term results. Eur J Cardiothorac Surg. 2004;25:742-7.

11. Elkins RC, Knott-Craig CJ, Ward KE, Lane MM. The Ross operation in children: 10-year experience. Ann Thorac Surg. 1998;65:496-502.

12. Kadner A, Raisky O, Degandt A, Tamisier D, Bonnet D, Sidi D, et al. The Ross procedure in infants and young children. Ann Thorac Surg. 2008;85:803-8.

13. Brown JW, Ruzmetov M, Vijay P, Hoyer MH, Girod D, Rodefeld MD, et al. Operative results and outcomes in children with Shone's anomaly. Ann Thorac Surg. 2005;79:1358-65.

14. Oka N, Al-Radi O, Alghamdi AA, Kim S, Caldarone CA. Ross-Konno procedure with mitral valve surgery. Ann Thorac Surg. 2010;89:1366-70.

15. Takkenberg JJ, Klieverik LM, Schoof PH, van Suylen RJ, van Herwerden LA, Zondervan PE, et al. The Ross procedure: a systematic review and meta-analysis. Circulation. 2009;119:222-8.

16. El-Hamamsy I, Eryigit Z, Stevens LM, Sarang Z, George R, Clark L, et al. Longterm outcomes after autograft versus homograft aortic root replacement in adults with aortic valve disease: a randomised controlled trial. Lancet. 2010;376: 524-31.

17. Alsoufi B, Al-Halees Z, Manlhiot C, McCrindle BW, Kandeel M, Al-Joufan M, et al. Superior results following the Ross procedure in patients with congenital heart disease. J Heart Valve Dis. 2010;19:269-77.

18. Tweddell JS, Pelech AN, Frommelt PC, Jaquiss RD, Hoffman GM, Mussatto KA, et al. Complex aortic valve repair as a durable and effective alternative to valve replacement in children with aortic valve disease. J Thorac Cardiovasc Surg. 2005;129:551-8.

19. Aicher D, Fries R, Rodionycheva S, Schmidt K, Langer F, Schafers HJ. Aortic valve repair leads to a low incidence of valve-related complications. Eur J Cardiothorac Surg. 2010;37:127-32.

20. Kobayashi J. Stentless aortic valve replacement: an update. Vasc Health Risk Manag. 2011;7:345-51.

21. Klieverik LM, Takkenberg JJ, Bekkers JA, Roos-Hesselink JW, Witsenburg M, Bogers AJ. The Ross operation: a Trojan horse? Eur Heart J. 2007;28: 1993-2000.

22. Jonas RA. The Ross procedure is not the procedure of choice for the teenager requiring aortic valve replacement. Semin Thorac Cardiovasc Surg Pediatr Card Surg Annu. 2005;176-80.

23. Rabkin-Aikawa E, Aikawa M, Farber M, Kratz JR, Garcia-Cardena G, Kouchoukos NT, et al. Clinical pulmonary autograft valves: pathologic evidence of adaptive remodeling in the aortic site. J Thorac Cardiovasc Surg. 2004;128: 552-61.

24. Yacoub MH, El-Hamamsy I. Valvular disease: the private life of tissue valves. Nat Rev Cardiol. 2010;7:424-6. 